\title{
The Prevalence of Depression and Anxiety Disorders Among Postgraduate Students in an Arabic Sample: A Cross-sectional Study
}

Asem A. Alageel ( $\square$ asemalageel@yahoo.com )

Imam Muhammad Ibn Saud Islamic University

Rayyan A. Alyahya

Imam Muhammad Ibn Saud Islamic University

Raed A Alghamdi

Imam Muhammad Ibn Saud Islamic University

Ban A. Alzaid

University Health Network

Aryaf. S Alsubaie

Imam Muhammad Ibn Saud Islamic University

Maha Alduraihem

Trabot center - Princess Nora University

Nader Alrahili

Imam Muhammad Ibn Saud Islamic University

Roger S. Mclntyre

University of Toronto

\section{Research Article}

Keywords: depression, anxiety, post graduate, insomnia, suicide ideation

Posted Date: September 2nd, 2021

DOI: https://doi.org/10.21203/rs.3.rs-143732/v2

License: (c) (1) This work is licensed under a Creative Commons Attribution 4.0 International License.

Read Full License 


\section{Abstract}

Background: Depression and anxiety are indicators of mental health and quality of life. Studies found a high prevalence of depression and anxiety disorders among specific populations, such as medical students, residents and fellows. However, postgraduate students unarguably suffer from many private and career life stressors. Unfortunately, research about the prevalence of depression and anxiety among postgraduate students are greatly lacking.

Methods: A cross-sectional online survey; a self-questionnaire divided into five sections. Sociodemographic characteristics, the Patient Health Questionnaire for Depression (PHQ9), Generalized Anxiety Disorder 7 item (GAD7), insomnia and suicide.

Results: The number of participants was 1,005, The prevalence of depression and GAD that warrant treatments are $27.4 \%$ and $23.6 \%$, respectively. Most of the participants who screened positive for depression and GAD were not aware of having these disorders. Females were at a higher risk of depression (OR: 1.5, 95\% CL: 1.10 to 2.15) and GAD (OR:1.49, 95\% CL 1.07 to 2.07). Insomnia is associated significantly with depression $(P<0.001)$ and GAD $(P<0.001)$. Depression increases the risk for active suicide thoughts $(\mathrm{OR}=7.453)(\mathrm{P}<0.001)$.

Limitations: Due to the nature of cross-sectional studies, causal relationships cannot be identified.

Conclusion: We have identified a higher prevalence of depression and GAD among postgraduate students compared with the general population. However, they appear to be underrepresented in mental health literature, so further research is necessary.

\section{Background:}

Mental health encompasses our psychological, social, and emotional wellbeing. It is responsible for the ways in which individuals deal with daily stressors, process emotions, and react to everyday situations. It influences relationships and careers by guiding feelings of compassion and empathy, and allows individuals to make rational decisions. Mental health is an essential characteristic of every human being through all stages of life, from childhood and adolescence through to adulthood. Mental disorders have a negative impact on a person's behavior, mood, function and could eventually jeopardize their relationships, education, jobs, and lives by affecting their appetite, sleep, and energy; causing selfdestructive behaviors; and in extreme cases, leading to suicide[1].

Major Depressive Disorder (MDD) and Generalized Anxiety Disorder (GAD) are considered important indicators of mental health and overall quality of life. According to the American Psychiatric Association, MDD is a serious medical illness characterized by detrimental changes to the way an individual thinks, acts, and feels. It causes feelings of sadness and a loss of interest in participating in activities the individual once enjoyed. It may be associated with trouble sleeping (e.g., insomnia), lack of appetite, fatigue, feelings of guilt, and suicidal ideation. Depending on the severity of MDD, it can cause cognitive 
dysfunction impacting the ability to perform day-to-day home and work activities by leading to a variety of physical and emotional problems[2,3] .

According to the World Health Organization (WHO), between the years 2005 and 2015, the prevalence of MDD increased by $18.4 \%$ worldwide. More than 322 million people suffer from MDD, It is the most significant contributor to global disability, representing $4.3 \%$ of total disability-adjusted life years. It is predicted to become the second leading cause of the global disease burden by the year 2020 [4]. MDD, among other psychiatric disorders, is associated with suicide[1,5] as well as non-suicidal self-harm [6]. The cause of MDD is unknown; however, psychological and biological factors, as well as social stressors may play a role in the development of $\operatorname{MDD}[2,7]$.

Anxiety is a common element in one's life and may affect individuals positively or negatively. According to the APA, anxiety is "a normal reaction to stress and can be beneficial in some situations. It can alert us to dangers and help us prepare and pay attention." [2]. A person's reactions to anxiety depend on the strength and persistence of anxious feelings, the individual's personality and cognitive assessment of psychological stress, and social support [8]. GAD differs from normal feelings of nervousness or anxiousness and may involve an excessive fear of unlikely and hypothetical situations that negatively impacts productivity and day-to-day life. Anxiety disorders affect about $30 \%$ of adults at some point in their lives and are considered to be the most common mental health disorders [9]. In the United States, nationally representative samples have concluded that the lifetime prevalence of GAD is $5.1 \%[10]$ to $11.9 \%$ [11]. GAD is highly comorbid with other mood disorders; according to several studies, more than $70 \%$ of people with MDD also exhibit anxiety symptoms, and $40-70 \%$ meet the criteria for a GAD [12], Fortunately, these are treatable disorders, and early detection by recognizing high-risk populations could help in treating these individuals adequately and effectively. The burden of illness is high, and MDD can cause irreparable damage to the quality of life, including family life, career, and death by suicide [13].

The prevalence of depression and anxiety disorders is higher in specific populations. For example, a systematic review and meta-analysis investigated the mental health of medical students by examining data from 167 cross-sectional studies and 16 longitudinal studies conducted before September 17, 2016. The studies took place in 43 countries and had a total of 129,123 subjects. The meta-analysis showed that the prevalence of MDD and depressive symptoms among medical students was $27.2 \%$, and $11.1 \%$ of them had suicidal ideation [14]. Interns and medical residents were also more likely to be exposed to stress than the general public [15]. A separate study measured depression and emotional distress separately and found that even positive emotional stress could put a person at a higher risk for MDD. High levels of stress over a prolonged period are linked to increased rates of GAD, MDD, cardiovascular disease, and other serious health issues [16]. A study conducted in Canada on 1,805 medical residents, interns, and fellows suggested that poor stress management and long working hours in postgraduate training and residency programs may impact students' quality of life, social life, and sleep, and health, thus exposing them to a higher risk of MDD [15]. Questionnaires and stress tests (SRRS, LCUs, and SCL90-R) were administered to determine the reasons for such high levels of stress, and results showed that greater stress levels were related to self-expectations and recurrent evaluations of environmental factors 
(e.g., financial status and offspring) $[17,18]$. These studies showcase the impact stress can have as a predisposing factor to MDD and GAD. A systematic review that summarized data from 45 cross-sectional and longitudinal studies (17,560 individuals) from 1972 to 2012 estimated that $28.8 \%$ of medical residents have MDD, with an increased prevalence with each passing year. MDD has been linked to lowerquality patient care and an increase in medical errors due to an overall decrease in performance [19]. Previous studies have shown that university students suffer a great deal of mental instability, especially MDD, compared to other populations. This may be due in part to the transition between adolescence and adulthood. A study conducted in China on 6000 university students concluded that $40.1 \%$ of the students had borderline clinical MDD, while $8.4 \%$ and $3.3 \%$ had moderate and severe MDD, respectively [7]. In conclusion, due to a variety of specific stressors that impact their quality of life, medical students and residents seem to have an increased risk of MDD and GAD in comparison to other populations.

Graduate students perceive their educational experience to be highly stressful and, therefore, have often scored above average on self-assessed stress scores [20]. A study of nursing graduate students found that $50.9 \%$ felt moderate stress, while $22.8 \%$ experienced a high level of stress, especially during examination-related activities. The stress was associated with poorer academic performance, reduced cognitive ability, compromised coping, and uncompleted graduate studies. Moreover, it was associated with physical symptoms such as headaches, reduced appetite, and disturbances in sleep patterns [17]. The choice of postgraduate students as subjects for this research is due to the lack of research showcasing MDD and GAD in this group. However, it is believed that this group suffers more stressors (financial, offspring, and educational) that can trigger MDD and GAD [21]. This thesis aims to ascertain the prevalence of MDD and GAD in Arabic postgraduate students in the middle east.

\section{Methods:}

\section{Study design}

This study was approved by the Institutional Review Board (IRB) of Imam Mohammad ibn Saud Islamic University in Riyadh, Saudi Arabia. A web-based Arabic cross-sectional survey for depression and anxiety amongst Arabian postgraduate students was utilized. The survey was distributed to participants in April 2019 and ended in June 2019. Two main advantages were considered for using a web-based survey: web-based surveys have shown to be just as reliable as phone-based and email-based surveys [22], and maybe preferable to phone interviews, especially when it comes to sensitive topics [23], Our targeted population were Arabian postgraduate students, the survey was disseminated through email, Twitter, Facebook, and an instant messaging service called WhatsApp. The Arabic population in the Middle East were identified by the universities and colleges they were attending; Studying in Arabic universities meant they all participants were Arabic, furthermore, those who were studying at schools outside of the Middle East were confirmed to be Arabs from the Middle East studying abroad. In the form of a checkbox, informed consent from participants was required to submit their answers, permitting us to use all the data they shared in our survey anonymously. The survey was a self-administered questionnaire divided into five sections. The first section concerned socio-demographic characteristics (such as age and gender, 
among others). The second and third sections included the Arabic-validated version of the Patient Health Questionnaire for Depression (PHQ9) and Generalized Anxiety Disorder (GAD7). The fourth section contained the Athens Insomnia Scale (AIS), and the fifth section encompassed suicidality.

We chose Major Depressive Disorder scale, $\mathrm{PHQ}-9$, in the second section because it incorporates the nine items of DSM depression criteria with other leading major depressive symptoms into a brief self-report instrument. A validated Arabic version of PHQ-9 was used. The Arabic version of PHQ-9 had an internal consistency reliability of 0.857 calculated using Cronbach's alpha [24]. We used the cut-off point of 10 to diagnose clinically significant depression, we then further classified the depressed participants to clinically significant, moderately severe, and severe. A clinically significant depression score ranged from 10-14, a moderately severe score ranged from 15-19, and a severe depression score was greater than 20.

The GAD-7 scale for Generalized Anxiety Disorder was implemented in the third section of our survey. GAD-7 represents an anxiety measure based on seven items which are scored from zero to three. The scale score can range from 0 to 21. In our survey, we used a validated Arabic version of GAD-7. The internal consistency reliability was measured using Cronbach's alpha with a result of 0.763 [24]. At the cut-off score of 10 , both sensitivity and specificity exceed .0.8. [25]. Any participant with a score of 10 was considered to have clinically significant general anxiety disorder [26]. These participants were then classified into clinically significant GAD and severe GAD categories based on scores of 10, 15+, respectively. Participants who scored $15+$ in PHQ-9 and GAD-7 warranted active treatment $[26,27]$.

Athens Insomnia Scale (AIS) was the fourth section in our survey, and was found to be valid and consistent as a reliable tool for detecting insomnia. The scale consists of 8 questions with answers that are scored from 0 to 3 . The English version with a cut-off score of 6 had an optimum specificity of $85 \%$ and sensitivity of $93 \%$ [28]. The scale has a positive predictive value (PPV) of $41 \%$ and a negative predictive value (NPV) of $99 \%$ [28]. In the present study, any participant with a score of 6 or more was considered to have insomnia. We used a version of the scale that was methodically translated to Arabic by Toronto Sleep Clinics. An English-speaking healthcare professional whose mother tongue is Arabic, translated the scale from English, and using the same approach as the first translation, back-translation to English was done by another translator. A few English-speaking translators reviewed the transcript for any problematic contextual discrepancies, however, this has not been tested yet.

The fifth section of our survey included four questions about suicide to determine suicidal ideation, suicide planning, and previous attempts of suicide amongst our participants. The four questions were presented as statements, and participants were presented with three choices to best represent their current situation. Choices included: always, sometimes, and never. The statement for the question about death wishes was, "I think of death and wish to die." The statement for the question about suicide planning was, "I have a clear plan to commit suicide." The statement for the question about suicidal thinking was, "During the past few weeks, I thought about suicide." The statement about previous suicide attempts was, "I have tried to commit suicide before. "These questions were inspired by The Scale for 
Suicide Ideation (SSI) [29], but due to the lengthy nature of the scale, which is 19 questions, we did not use the scale.

\section{Data analysis}

Data were analyzed using Statistical Package for Social Studies (SPSS 22; IBM Corp., New York, NY, USA). Continuous variables were expressed as mean \pm standard deviation and categorical variables were expressed as percentages. The t-test and one-way ANOVA were used for continuous variables. Univariate and multivariate were used to assess the risk factors for depression and anxiety. A p-value $<0.05$ was considered statistically significant.

\section{Results:}

1460 people accessed our survey. However, 1005 completed the questionnaire, representing a response rate of $68.8 \%$. Among completed questionnaires, 267 of the respondents were males (26.6\%), and 738 were females (73.4\%). 484 (48.2\%) of the respondents were between $20-29$ years of age, $470(46.8 \%)$ were between the ages of 30-40, and 51 (5.1\%) were above 40 years old. Marital status was included in the questionnaire and the options included: single, married, and divorced. Participants' marital status results were $478(47.6 \%), 475(47.3 \%)$, and $52(5.2 \%)$, respectively. The number of children ranged between 0 to +4 , with the majority of participants having 0 children at $575(57.2 \%)$, participants who had 1-3 children were 332 (32.9\%), while participants who had 4+ children were 98 (9.8\%). Participants were asked about their education level; the two categories were Masters and PhD students. Results revealed that 743 (74.3\%) of participants were Masters students and 257 (25.7\%) were PhD students. The majority of the participants were in the process of completing the first and second years of their postgraduate studies, 352 (35\%) and 259 (25.8\%), respectively. (Table 1).

$598(59.5 \%)$ of our population had clinically significant depression, $133(13.2 \%)$ had moderate to severe MDD, and 143 (14.2\%) had severe MDD. We used GAD7 to measure the prevalence of GAD, $552(54.9 \%)$ of participants had clinically significant GAD, while 237 (23.6\%) showcased results diagnostic of severe GAD (Spitzer, Kroenke, Williams, \& Löwe, 2006) (Table 2) Our statistical analysis concluded that females had a higher risk of MDD $(O R=1.53)$ and GAD $(O R=1.49)(P<0.001)$. Single participants showed a higher prevalence of MDD $(P<0.001)$ and GAD $(P=0.001)$. Age difference did not have any statistical significance when it comes to MDD. However, GAD showed an increase in prevalence with younger participants $(P=0.011)$. The number of children revealed no statistical significance, nor did educational level, academic year, father's education, or students on scholarships outside the country (Table 3). Regarding insomnia, we found that 514 (74.06\%) who were identified to have insomnia had MDD $(P<0.001)$, and $135(19.45 \%)$ had severe MDD $(P<0.001) .472(68.01 \%)$ of those who had insomnia were also experiencing GAD $(P<0.001)$, and $224(32.28 \%)$ had severe GAD $(P<0.001)$ (Table 3$)$. Interestingly, 499 (83.44\%) and $463(46.07 \%)$ of our population did not know they had MDD and clinically significant GAD. 
Four suicidal ideation questions were asked. The participants were given a statement, and were provided with the following responses: "Never," "Sometimes," or "Always," the first statement was "I think of death and wish to die," $4 \%$ of our participants chose "Always," moreover, $95 \%$ of them had MDD ( $<<0.001), 65 \%$ suffered severe MDD ( $P<0.001), 87 \%$ of them had GAD $(P<0.001)$, and $62 \%$ had severe $G A D(P<0.001)$. Those who answered "sometimes" included $22.4 \%$ of our population, $87.1 \%$ of them had MDD $(P<0.001)$, $35.1 \%$ had severe $\operatorname{MDD}(P<0.001)$, 75.1\% had GAD $(P<0.001)$, and $37.7 \%$ had severe $\operatorname{GAD}(P<0.001)$. Those who answered "never," encompassed $73.6 \%$ of our population, and $49.1 \%$ of them had MDD $(P<0.001)$, $5.14 \%$ had severe MDD $(P<0.001), 47 \%$ had GAD $(P<0.001)$, and $17.1 \%$ had severe GAD $(P<0.001)$. Participants with MDD (OR=7.797) $(P<0.001)$ and severe MDD $(O R=12.123)(P<0.001)$ had an increased risk of thinking about death. The second statement was "During the past few weeks, I thought about suicide". $1.5 \%$ of our participants chose "Always," $86.6 \%$ and $66.6 \%$ of them had MDD and severe MDD respectively $(P<0.001) .80 \%$ had GAD ( $P<0.001), 66.6 \%$ had and severe $G A D(P<0.001) .6 .1 \%$ answered "sometimes", and $91.8 \%$ of them had MDD ( $P<0.001)$, 47.5\% had severe MDD $(P<0.001), 86.8 \%$ had GAD $(P<0.001)$, and $42.6 \%$ had severe GAD $(P<0.001)$. Those who had MDD (OR=7.453) $(P<0.001)$, severe MDD $(O R=8.361)(P<0.001), G A D(O R=5.363)(P<0.001)$, and severe GAD $(O R=3.260)(P<0.001)$ were at an increased risk of thinking about comitting suicide. In total, $7.5 \%$ of our participants reported suicidal ideation. (Table 4, 5 \& 6)

The third statement was, "I have a clear plan to commit suicide." 96.7\% (n=972) participants answered "never", 2.6\% $(n=26)$ answered "sometimes", and 0.7\% $(n=7)$ answered "always". 58.54\% $(n=569)$ of people who answered "never" had MDD, while 12.55\% ( $n=122)$ of them had severe MDD. $96.15 \%(n=25)$ and $73.08 \%(n=19)$ of people who answered "sometimes" had MDD and severe MDD, respectively. $57.14 \%$ $(n=4)$ and $28.57 \%(n=2)$ of people who answered "always" had MDD and severe MDD, respectively. These results show a significant relationship between suicide planning, MDD $(P=.001)$, and severe MDD $(P=.001) .53 .91 \%(n=524)$ and $22.33 \%(n=217)$ of people who answered "never" had GAD and severe GAD, respectively. $92.31 \%(n=24)$ and $65.38 \%(n=17)$ of people who answered "sometimes" had GAD and severe GAD, respectively. $57.14 \%(n=4)$ and $42.86 \%(n=3)$ of people who answered "always" had GAD and severe GAD, respectively. These results show a significant relationship between suicide planning, GAD $(P=.001)$, and severe GAD $(P=.022)$. (Table 4 \& 5)

The fourth statement was, "I have tried to commit suicide before." 95.1\% ( $n=956)$ answered "never", 4.2\% $(n=42)$ answered "sometimes", and 0.7\% $(n=7)$ answered "always". 58.47\% $(n=559)$ and $12.76 \%(n=122)$ of the people who answered "never" had MDD and severe MDD, respectively. $80.95 \%(n=34)$ and $40.48 \%$ $(n=17)$ of people who answered "sometimes" had MDD and severe MDD, respectively. $71.43 \%(n=5)$ and $57.14 \%(n=4)$ of people who answered "always" had MDD and severe MDD, respectively. These results show a significant relationship between suicidal attempts, MDD ( $=.012)$, and severe MDD $(P=.001)$.

$53.97 \%(n=516)$ and $22.70 \%(n=217)$ of people who answered "never" had anxiety and severe GAD, respectively. $71.43 \%(n=30)$ and $35.71 \%(n=15)$ of people who answered "sometimes" had GAD and severe GAD, respectively. $85.71 \%(n=6)$ and $71.43 \%(n=5)$ of people who answered "always" had GAD and 
severe GAD, respectively. These results show a significant relationship between suicidal attempts, GAD $(P=.001)$, and severe GAD ( $P=.002)$ (Table $4 \& 5)$.

\section{Discussion:}

The percentage of the participants in our study who screened positive for MDD was $59.5 \%$, which is higher than the prevalence of previous similar studies. For example, the UC Berkeley report showed that $43-46 \%$ of bioscience graduate students had MDD [30]. Another study published in 2018 surveyed 2,279 Ph.D. and Masters students from 26 countries and 234 institutions using PHQ-9 and revealed a prevalence of $39 \%$ MDD among the postgraduate population, as compared to $6 \%$ of the general population [31]. On the other hand, our study result may be consistent with the prevalence of MDD among medical students (55.9\%) [14]. Moreover, the prevalence of MDD of our graduate students is less than the MDD prevalence of college students in some previous studies. For instance, a systematic review of 24 articles studying the prevalence of MDD among university students between the years 1990 and 2010, showed that the prevalence of MDD reached up to $84.5 \%$ [32]. Using an Arabic version of the Hamilton Score, Egyptian university students had a $71 \%$ prevalence of mild MDD, while $37.6 \%$ had moderate MDD [33]. When it comes to the treatment, the prevalence of MDD that warrants treatment in our study is $27.4 \%$, based on the interpretation of the PHQ9 scale [34].

A study used GAD-7 to evaluate the prevalence of GAD concluded that $41 \%$ of graduate students suffered moderate to severe GAD, which is about six times the prevalence of GAD among the general population [31]. Using the same scale, our study resulted in a prevalence of moderate to severe GAD of $54.9 \%$; Furthermore, $23.6 \%$ of our population suffered with severe GAD that warrants active treatment $[26,35$, 36]. Marital status seems to have an impact on the risk of developing MDD. Our study found a relationship between being single and mental health issues, whereby non-married participants exhibited a higher prevalence of GAD and MDD. consistent with a previous study regarding the prevalence of MDD among medical residents, interns, and fellows which concluded that single participants have a higher incidence of MDD [15].

Female participants had about a $(50 \%)$ higher risk of developing both MDD (OR $=1.378)$ and GAD (OR = 1.434) than males $(P=0.012)(P=0.016)$, which is consistent with the plethora of research findings from local and global literature studying the prevalence of $\operatorname{MDD}[4,7,15,37-40]$ Although age in this study had no statistical significance when it came to MDD, younger participants showcased a higher prevalence of GAD, corroborating a multitude of studies that have concluded that younger people have a higher risk of developing GAD and MDD [39, 41-43]. However, two studies in China and Ethiopia about mental illness found the opposite, wherein older participants had a higher risk of developing MDD [7, 44].

Sleep health is a reliable indicator of an individual's overall health and quality of life [45], including mental health. Several studies indicate that sleep disturbances may have a significant relationship to mental health [46-48]. Our questionnaire included the Athens Insomnia Scale to measure the prevalence of insomnia among our population. The results verified previous literature. Our study found a strong 
correlation between insomnia, MDD, and GAD. According to previous studies, sleep disturbances can be both a predictive factor and a consequence of MDD [49] and anxiety.

A study done in Saudi Arabia concluded that (49.9\%) of patients visiting primary health care facilities had symptoms of MDD [37]; furthermore, their study had a (19\%) prevalence of moderate to severe MDD. However, our study showed that $(27.4 \%)$ of the participants had moderate to severe MDD, which reflects a palpable increase of risk of MDD among postgraduate students in comparison to the adult population visiting primary healthcare in Saudi Arabia.

One of the devastating effects of mental illness, especially in MDD, and the 10th most significant cause of death in the united states [50], is suicide. It has been shown in out-patients who have completed the PHQ questionnaire, that the 9th item asking about suicidal ideation was a strong predictor of suicide attempts during the following year [51]. In an analysis of 24 studies, the rough summary prevalence of suicidal ideation by medical students, reported as having occurred over the past two weeks to the past 12 months, was $11.1 \%$ (2043/ 21002 individuals; 95\% Cl, 9.0\%-13.7\%) [14]. These numbers concurred with our results, where $7.5 \%$ of our participants have either always or sometimes thought about ending their own life. In another cross-sectional study of 1980 psychiatric residents from 22 countries, $12.3 \%(n=225)$ reported active suicidal ideation [52]. Comparing these results and our results with the results of surveys from the world health organization which showed that the general population prevalence of suicide ideation in developed countries is $2.0 \%$ and $2.1 \%$ in developing countries [53]. This highlights a significant increase of suicidal ideation amongst postgraduate students. This three-fold increase suggests that it is crucial for academic institutions to provide wellness programs focused on suicide and suicide prevention for their postgraduate students.

In our study, about $83 \%$ of participants who screened positive for MDD and GAD were not aware of already having these disorders, which reflects the lack of awareness and inadequate screening of mental disorders. According to systematic reviews on data from the World Health Organization WMH surveys, a minority of people with MDD received minimally adequate treatments, where 1 in 5 people with MDD received minimally adequate treatment in high-income countries, and 1 in 27 in low-income countries [54], Even when it comes to the most severe cases, there is a high level of worldwide unmet need for mental health care, where only a small fraction of cases receive little to no treatment, in both underdeveloped and developed nations throughout the world [55]. Furthermore, it appears that there are multiple reasons as to why there is such a high level of unmet need for treatment. For example, the low recognition and awareness of illness by people with mental health issues, poor countries had a population that lacked recognition for their symptoms and a need for treatment for their MDD treatment [54]. On the other hand, the unmet need for treatment may be due to national diminished mental healthcare investment and budget [56]. A study showed that wellness programs have a dramatic impact on the mental health of medical students by significantly reducing suicidal ideation among 3rd-year medical students [57]. A recent study highlighted the effects of suicide awareness materials with people who experienced suicidal ideation or had a history of suicide attempts. It was concluded from narratives of those who personally 
experienced suicidal ideation and attempts, that these resources provided a short-term protective effect [58], reflecting the potential protective effect of awareness on people with suicidal ideation.

\section{Limitations:}

Due to the nature of cross-sectional studies representing a single time point rather than a longitudinal observation, our study is therefore not guaranteed to be representative of the entire population. Crosssectional studies do not determine causation. Another limitation is that there is also the possibility of recall bias from participants. Since our study was distributed online, through emails and different social media outlets, it excludes people who experience MDD or GAD that do not have access to social media. Additionally, some individuals with MDD and GAD may feel uncomfortable participating in our study due to the societal stigma of mental illness. Thus, the study may include participants who are more receptive to the concept of mental illness and mental health. Furthermore, although the PHQ-9 is commonly used in clinical practice and known as the most used questionnaire when diagnosing MDD, it includes somatic symptoms such as fatigue and poor appetite, which can be attributed to other illnesses (e.g. heart disease, infections, cancer etc.). Therefore, our study risks the overestimation of the prevalence of MDD. Finally, this study did not include a fully validated suicidal ideation scale; therefore, interpretations of suicide data are not to be used as evidence, but as an indicator for our population.

\section{Conclusion:}

We have identified a higher prevalence of MDD and GAD among postgraduate students compared with the general population. Although our survey did not include a fully validated suicidal ideation scale, the prevalence of suicidal ideations and behaviors is alarming and should be further investigated in future research studies. Although students affected with MDD and GAD are highly educated, their awareness and understanding of mental health is not great enough to recognize their illness and seek help. Postgraduate students appear to be underrepresented in mental health literature therefore, further research is necessary to confirm these results, understand their mental health, and include possible associated risk factors. Last, we suggest launching awareness campaigns and wellness programs to promote and preserve the mental health of postgraduate students.

\section{Abbreviations}

MDD: Major Depressive Disorder, GAD: Generalized Anxiety Disorder, WHO: World Health Organization, PHQ9: Patient Health Questionnaire for Depression, AIS: Athens Insomnia Scale, PPV: positive predictive value, NPV: negative predictive value, SSI: Scale for Suicide Ideation.

\section{Declarations}

\section{Ethics approval and consent to participate}


In accordance with the WMA Declaration of Helsinki guidelines and the Vancouver protocol, this study was approved by the IRB of IMSIU in Riyadh, Saudi Arabia. Informed consent was obtained from all participants through a statement of agreement at the beginning of each questionnaire. Protection of the privacy of research subjects as well as confidentiality of their personal information was ensured. Each subject was adequately informed of the aims, methods, sources of funding, any possible conflicts of interest, institutional affiliations of the researcher, the anticipated benefits and potential risks of the study, the discomfort it may entail, post-study provisions, and all other relevant aspects of the study, in accordance with the WMA Declaration of Helsinki guidelines and the Vancouver protocol.

\section{Consent for publication}

Not applicable.

\section{Conflict of interest}

Dr. McIntyre reports grants from Stanley Medical Research Institute, and from CIHR/GACD/Chinese National Natural Research Foundation. and other relationships that may include consultations/speaker fees, from Lundbeck, Janssen, Shire, Purdue, Pfizer, Otsuka, Allergan, Takeda, Neurocrine, Sunovion, Minerva outside the submitted work.

All other authors declare that they have no conflicts of interest.

\section{Funding Source Declaration}

This research was supported by the Deanship of Scientific

Research, Al-Imam Mohammad Ibn Saud Islamic University (IMSIU), Saudi Arabia, Grant No. (18-11-13004).

\section{Contribution}

Conception and design of study was done by A. Alageel, R. Alyahya, R. Alghamdi and R. Mclntyre. Acquisition of data was done by A. Alageel, R. Alyahya, and R. Alghamdi. Analysis and/or interpretation of data was done by A. Alageel, R. Alyahya, N. Alrahili, and R. Alghamdi. A. Alageel, R. Alyahya, R. Alghamdi, B. Alzaid, A. Alsubaie, and M. Alduraihem wrote the main manuscript and prepared the tables. All authors reviewed and approved the manuscript.

\section{Data availability statement}


The data that support the findings of this study are not openly available and are available from the corresponding author upon request.

\section{Acknowledgements}

We would like to express our sincere gratitude to the Deanship of Academic Research, Al-Imam Mohammad Ibn Saud Islamic University (IMSIU), and SABIC Psychological Health Research \& Applications Chair (SPHRAC).

\section{References}

1. Bolton JM, Belik SL, Enns MW, Cox BJ, Sareen J: Exploring the correlates of suicide attempts among individuals with major depressive disorder: findings from the national epidemiologic survey on alcohol and related conditions. J Clin Psychiatry2008, 69(7):1139-1149.

2. What Is Depression?[https://www.psychiatry.org/patients-families/depression/what-is-depression]

3. McIntyre RS, Lee Y, Carmona NE, Subramaniapillai M, Cha DS, Lee J, Lee JH, Alageel A, Rodrigues NB, Park Cet al: Characterizing, Assessing, and Treating Cognitive Dysfunction in Major Depressive Disorder. Harv Rev Psychiatry2018, 26(5):241-249.

4. World Health O: Depression and other common mental disorders: global health estimates. In. Geneva: World Health Organization; 2017.

5. Nock MK, Borges G, Bromet EJ, Alonso J, Angermeyer M, Beautrais A, Bruffaerts R, Chiu WT, de Girolamo G, Gluzman Set al: Cross-national prevalence and risk factors for suicidal ideation, plans and attempts. Br J Psychiatry2008, 192(2):98-105.

6. Nitkowski D, Petermann F: [Non-suicidal self-injury and comorbid mental disorders: a review]. Fortschr Neurol Psychiatr2011, 79(1):9-20.

7. Chen L, Wang L, Qiu XH, Yang XX, Qiao ZX, Yang YJ, Liang Y: Depression among Chinese university students: prevalence and socio-demographic correlates. PLoS One2013, 8(3):e58379.

8. Volpe JJ: Overview: normal and abnormal human brain development. Ment Retard Dev Disabil Res Rev2000, 6(1):1-5.

9. What Are Anxiety Disorders?[https://www.psychiatry.org/patients-families/anxiety-disorders/whatare-anxiety-disorders]

10. Wittchen HU, Zhao S, Kessler RC, Eaton WW: DSM-III-R generalized anxiety disorder in the National Comorbidity Survey. Arch Gen Psychiatry1994, 51(5):355-364.

11. Kessler RC, Gruber M, Hettema JM, Hwang I, Sampson N, Yonkers KA: Co-morbid major depression and generalized anxiety disorders in the National Comorbidity Survey follow-up. Psychol Med2008, 38(3):365-374.

12. Wu Z, Fang Y: Comorbidity of depressive and anxiety disorders: challenges in diagnosis and assessment. Shanghai Arch Psychiatry2014, 26(4):227-231. 
13. Feightner JW, Worrall G: Early detection of depression by primary care physicians. CMAJ1990, 142(11):1215-1220.

14. Rotenstein LS, Ramos MA, Torre M, Segal JB, Peluso MJ, Guille C, Sen S, Mata DA: Prevalence of Depression, Depressive Symptoms, and Suicidal Ideation Among Medical Students: A Systematic Review and Meta-Analysis. JAMA2016, 316(21):2214-2236.

15. Hsu K, Marshall V: Prevalence of depression and distress in a large sample of Canadian residents, interns, and fellows. Am J Psychiatry1987, 144(12):1561-1566.

16. Berkel KV, \& Reeves, B. : Stress among Graduate Students in Relation to Health Behaviors. College student journal2017, 51:498-510.

17. Brown $\mathrm{K}$, Anderson-Johnson $\mathrm{P}, \mathrm{McPherson} \mathrm{AN}$ : Academic-related stress among graduate students in nursing in a Jamaican school of nursing. Nurse Educ Pract2016, 20:117-124.

18. Toews JA, Lockyer JM, Dobson DJ, Brownell AK: Stress among residents, medical students, and graduate science (MSc/PhD) students. Acad Med1993, 68(10 Suppl):S46-48.

19. Mata DA, Ramos MA, Bansal N, Khan R, Guille C, Di Angelantonio E, Sen S: Prevalence of Depression and Depressive Symptoms Among Resident Physicians: A Systematic Review and Meta-analysis. JAMA2015, 314(22):2373-2383.

20. Pfeifer TA, Kranz PL, Scoggin AE: Perceived stress in occupational therapy students. Occup Ther Int2008, 15(4):221-231.

21. Shete A, Garkal KD: A study of stress, anxiety, and depression among postgraduate medical students. CHRISMED Journal of Health and Research2015, 2:119.

22. McCabe SE: Comparison of web and mail surveys in collecting illicit drug use data: a randomized experiment. J Drug Educ2004, 34(1):61-72.

23. Aday L, Cornelius, LJ: Designing and conducting health surveys: a comprehensive guide. (2nd ed.); 1996.

24. AlHadi AN, AlAteeq DA, Al-Sharif E, Bawazeer HM, Alanazi H, AlShomrani AT, Shuqdar RM, AlOwaybil R: An arabic translation, reliability, and validation of Patient Health Questionnaire in a Saudi sample. Ann Gen Psychiatry2017, 16:32.

25. Plummer F, Manea L, Trepel D, McMillan D: Screening for anxiety disorders with the GAD-7 and GAD2: a systematic review and diagnostic metaanalysis. Gen Hosp Psychiatry2016, 39:24-31.

26. Spitzer RL, Kroenke K, Williams JB, Lowe B: A brief measure for assessing generalized anxiety disorder: the GAD-7. Arch Intern Med2006, 166(10):1092-1097.

27. Kroenke K, Spitzer RL, Williams JB: The PHQ-9: validity of a brief depression severity measure. J Gen Intern Med2001, 16(9):606-613.

28. Soldatos CR, Dikeos DG, Paparrigopoulos TJ: The diagnostic validity of the Athens Insomnia Scale. $J$ Psychosom Res2003, 55(3):263-267.

29. Beck AT, Kovacs $M$, Weissman A: Assessment of suicidal intention: the Scale for Suicide Ideation. $J$ Consult Clin Psycho/1979, 47(2):343-352. 
30. Berkeley GAU: Graduate Student Happiness and Well-being Report. In.; 2014.

31. Evans TM, Bira L, Gastelum JB, Weiss LT, Vanderford NL: Evidence for a mental health crisis in graduate education. Nat Biotechno/2018, 36(3):282-284.

32. Ibrahim AK, Kelly SJ, Adams CE, Glazebrook C: A systematic review of studies of depression prevalence in university students. $J$ Psychiatr Res2013, 47(3):391-400.

33. Ibrahim AK, Kelly SJ, Glazebrook C: Reliability of a shortened version of the Zagazig Depression Scale and prevalence of depression in an Egyptian university student sample. Compr Psychiatry2012, 53(5):638-647.

34. Kroenke K, Spitzer RL, Williams JB: The PHQ-15: validity of a new measure for evaluating the severity of somatic symptoms. Psychosom Med2002, 64(2):258-266.

35. Kroenke K, Spitzer RL, Williams JB, Monahan PO, Lowe B: Anxiety disorders in primary care: prevalence, impairment, comorbidity, and detection. Ann Intern Med2007, 146(5):317-325.

36. Ruiz MA, Zamorano E, Garcia-Campayo J, Pardo A, Freire O, Rejas J: Validity of the GAD-7 scale as an outcome measure of disability in patients with generalized anxiety disorders in primary care. $J$ Affect Disord2011, 128(3):277-286.

37. Al-Qadhi W, Ur Rahman S, Ferwana MS, Abdulmajeed IA: Adult depression screening in Saudi primary care: prevalence, instrument and cost. BMC Psychiatry2014, 14:190.

38. Ibrahim N, Al-Kharboush D, El-Khatib L, Al-Habib A, Asali D: Prevalence and Predictors of Anxiety and Depression among Female Medical Students in King Abdulaziz University, Jeddah, Saudi Arabia. Iran J Public Health2013, 42(7):726-736.

39. Iqbal S, Gupta S, Venkatarao E: Stress, anxiety and depression among medical undergraduate students and their socio-demographic correlates. Indian J Med Res2015, 141(3):354-357.

40. Sokratous S, Merkouris A, Middleton N, Karanikola M: The prevalence and socio-demographic correlates of depressive symptoms among Cypriot university students: a cross-sectional descriptive co-relational study. BMC Psychiatry2014, 14:235.

41. Al-Khathami AD, Ogbeide DO: Prevalence of mental illness among Saudi adult primary-care patients in Central Saudi Arabia. Saudi Med J2002, 23(6):721-724.

42. Al-Kuwari MF, Samya \& Al-Emadi, Nada \& Ghanim, Issa \& Ahmad, Abdelmajeed.: Prevalence and determinants of depression among primary health care attendees in Qatar 2008.. Middle East Journal Of Family Medicine2010.

43. Maurer DM: Screening for depression. Am Fam Physician2012, 85(2):139-144.

44. Hunduma G, Girma M, Digaffe T, Weldegebreal F, Tola A: Prevalence and determinants of common mental illness among adult residents of Harari Regional State, Eastern Ethiopia. Pan Afr Med J2017, 28:262.

45. Buysse DJ: Sleep health: can we define it? Does it matter? Sleep2014, 37(1):9-17.

46. Baglioni C, Battagliese G, Feige B, Spiegelhalder K, Nissen C, Voderholzer U, Lombardo C, Riemann D: Insomnia as a predictor of depression: a meta-analytic evaluation of longitudinal epidemiological 
studies. J Affect Disord2011, 135(1-3):10-19.

47. Fan F, Zhou Y, Liu X: Sleep Disturbance Predicts Posttraumatic Stress Disorder and Depressive Symptoms: A Cohort Study of Chinese Adolescents. J Clin Psychiatry2017, 78(7):882-888.

48. Yu J, Rawtaer I, Fam J, Jiang MJ, Feng L, Kua EH, Mahendran R: Sleep correlates of depression and anxiety in an elderly Asian population. Psychogeriatrics2016, 16(3):191-195.

49. Barateau L, Lopez R, Franchi JA, Dauvilliers Y: Hypersomnolence, Hypersomnia, and Mood Disorders. Curr Psychiatry Rep2017, 19(2):13.

50. Sherry L. Murphy BSJX, M.D.; and Kenneth D. Kochanek, M.A., : Deaths: Preliminary Data for 2010. National Vital Statistics Reports2012, 60:1-31.

51. Simon GE, Rutter CM, Peterson D, Oliver M, Whiteside U, Operskalski B, Ludman EJ: Does response on the PHQ-9 Depression Questionnaire predict subsequent suicide attempt or suicide death? Psychiatr Serv2013, 64(12):1195-1202.

52. Jovanovic N, Beezhold J, Tateno M, Barrett E, Vlachos I, Fiorillo A, Hanon C, Kazakova O, Nawka A, Wuyts Pet al: Depression and suicidality among psychiatric residents - results from a multi-country study. J Affect Disord2019, 249:192-198.

53. Borges G, Nock MK, Haro Abad JM, Hwang I, Sampson NA, Alonso J, Andrade LH, Angermeyer MC, Beautrais A, Bromet Eet al: Twelve-month prevalence of and risk factors for suicide attempts in the World Health Organization World Mental Health Surveys. J Clin Psychiatry2010, 71(12):1617-1628.

54. Thornicroft G, Chatterji S, Evans-Lacko S, Gruber M, Sampson N, Aguilar-Gaxiola S, Al-Hamzawi A, Alonso J, Andrade L, Borges Get al: Undertreatment of people with major depressive disorder in 21 countries. Br J Psychiatry2017, 210(2):119-124.

55. Wang PS, Aguilar-Gaxiola S, Alonso J, Angermeyer MC, Borges G, Bromet EJ, Bruffaerts R, de Girolamo G, de Graaf R, Gureje Oet al: Use of mental health services for anxiety, mood, and substance disorders in 17 countries in the WHO world mental health surveys. Lancet2007, 370(9590):841-850.

56. Saxena S, Sharan P, Saraceno B: Budget and financing of mental health services: baseline information on 89 countries from WHO's project atlas. J Ment Health Policy Econ2003, 6(3):135-143.

57. Thompson D, Goebert D, Takeshita J: A program for reducing depressive symptoms and suicidal ideation in medical students. Acad Med2010, 85(10):1635-1639.

58. Niederkrotenthaler T, Till B: Effects of awareness material featuring individuals with experience of depression and suicidal thoughts on an audience with depressive symptoms: Randomized controlled trial. J Behav Ther Exp Psychiatry2020, 66:101515.

\section{Tables}




\begin{tabular}{|c|c|c|c|}
\hline \multicolumn{4}{|c|}{ Table 1} \\
\hline & & Number & $\%$ \\
\hline \multirow[t]{2}{*}{ Gender } & Male & 267 & 26.6 \\
\hline & Female & 738 & 73.4 \\
\hline \multirow[t]{3}{*}{ Age } & $20-29$ & 484 & 48.2 \\
\hline & $30-40$ & 470 & 46.8 \\
\hline & $40+$ & 51 & 5.1 \\
\hline \multirow[t]{3}{*}{ Marital status } & Single & 478 & 47.6 \\
\hline & Married & 475 & 47.3 \\
\hline & Divorced & 52 & 5.2 \\
\hline \multirow[t]{5}{*}{ Number of children } & 0 & 575 & 57.2 \\
\hline & 1 & 110 & 10.9 \\
\hline & 2 & 119 & 11.8 \\
\hline & 3 & 103 & 10.2 \\
\hline & $4+$ & 98 & 9.8 \\
\hline \multirow[t]{2}{*}{ Educational level } & Master & 743 & 74.3 \\
\hline & PHD & 257 & 25.7 \\
\hline \multirow[t]{5}{*}{ Academic year } & First & 352 & 35.0 \\
\hline & Second & 259 & 25.8 \\
\hline & Third & 147 & 14.6 \\
\hline & Fourth & 107 & 10.6 \\
\hline & Fifth & 140 & 13.9 \\
\hline \multirow[t]{5}{*}{ Education of father } & Primary & 209 & 20.9 \\
\hline & Intermediate & 135 & 13.5 \\
\hline & Secondary & 208 & 20.8 \\
\hline & University & 301 & 30.1 \\
\hline & High education & 146 & 14.6 \\
\hline
\end{tabular}


Table 2

Prevalence of Depression and Anxiety disorders

\begin{tabular}{|lll|}
\hline & Number & $\%$ \\
\hline Depression & 598 & 59.5 \\
\hline Moderate to Severe Depression & 133 & 13.2 \\
\hline Severe Depression & 143 & 14.2 \\
\hline Clinically significant Anxiety Disorder & 552 & 54.9 \\
\hline Severe Anxiety Disorder & 237 & 23.6 \\
\hline
\end{tabular}




\section{Table 3}

Mean of the total SCORE FOR PHQ9 (Depression) and GAD7 (Anxiety disorder) Questionnaire by characteristics of the participants

\begin{tabular}{|c|c|c|c|c|c|c|c|}
\hline & & \multicolumn{3}{|c|}{ PHQ9 (Depression) } & \multicolumn{3}{|c|}{ GAD7 (Anxiety) } \\
\hline & & Mean & SD & $P$ value & Mean & SD & $P$ value \\
\hline \multirow[t]{2}{*}{ Gender } & Male & 10.47 & 6.11 & \multirow[t]{2}{*}{$<0.001^{\star}$} & 9.34 & 5.52 & \multirow[t]{2}{*}{$<0.001^{*}$} \\
\hline & Female & 12.22 & 6.11 & & 11.22 & 5.61 & \\
\hline \multirow[t]{3}{*}{ Age } & $20-29$ & 12.13 & 6.07 & \multirow[t]{3}{*}{0.147} & 11.10 & 5.63 & \multirow[t]{3}{*}{$0.011^{\star}$} \\
\hline & $30-40$ & 11.47 & 6.06 & & 10.55 & 5.59 & \\
\hline & $40+$ & 10.88 & 7.51 & & 8.73 & 5.93 & \\
\hline \multirow[t]{3}{*}{ Marital status } & Single & 12.71 & 6.08 & \multirow[t]{3}{*}{$<0.001 *$} & 11.40 & 5.57 & \multirow[t]{3}{*}{$0.001 *$} \\
\hline & Married & 10.80 & 6.04 & & 10.10 & 5.60 & \\
\hline & Divorced & 11.77 & 6.59 & & 10.15 & 6.16 & \\
\hline \multirow[t]{5}{*}{ Number of children } & 0 & 12.33 & 6.11 & \multirow[t]{5}{*}{$0.005^{\star}$} & 11.03 & 5.64 & \multirow[t]{5}{*}{0.114} \\
\hline & 1 & 10.26 & 6.00 & & 9.92 & 5.64 & \\
\hline & 2 & 10.87 & 5.83 & & 9.93 & 5.21 & \\
\hline & 3 & 11.61 & 6.54 & & 11.15 & 5.98 & \\
\hline & $4+$ & 11.29 & 6.23 & & 10.29 & 5.78 & \\
\hline \multirow[t]{2}{*}{ Educational level } & Master & 11.64 & 6.17 & \multirow[t]{2}{*}{0.331} & 10.57 & 5.62 & \multirow[t]{2}{*}{0.176} \\
\hline & PHD & 12.08 & 6.17 & & 11.12 & 5.70 & \\
\hline \multirow[t]{5}{*}{ Academic year } & First & 11.48 & 5.87 & \multirow[t]{5}{*}{0.181} & 10.47 & 5.45 & \multirow[t]{5}{*}{0.251} \\
\hline & Second & 11.47 & 6.40 & & 10.98 & 6.01 & \\
\hline & Third & 11.88 & 6.05 & & 10.57 & 5.75 & \\
\hline & Fourth & 11.69 & 5.64 & & 10.08 & 5.33 & \\
\hline & Fifth & 12.91 & 6.77 & & 11.50 & 5.56 & \\
\hline \multirow[t]{5}{*}{ Education of father } & Primary & 11.97 & 6.15 & \multirow[t]{5}{*}{0.955} & 10.88 & 5.65 & \multirow[t]{5}{*}{0.927} \\
\hline & Intermediate & 11.80 & 5.70 & & 10.47 & 5.24 & \\
\hline & Secondary & 11.85 & 6.58 & & 10.50 & 5.75 & \\
\hline & University & 11.67 & 6.06 & & 10.80 & 5.62 & \\
\hline & High education & 11.47 & 6.23 & & 10.84 & 5.98 & \\
\hline
\end{tabular}




\begin{tabular}{|llll|}
\hline \multicolumn{1}{|c}{$\begin{array}{c}\text { Table } 4 \\
\text { Suicide data }\end{array}$} & & & \\
\hline I think of death and wish to die & & Number & $\%$ \\
\hline & Never & 740 & 73.6 \\
\hline During the past few weeks, I thought about suicide & Never & 929 & 92.4 \\
& Sometimes & 225 & 22.4 \\
\hline I have a clear plan to commit suicide & Sometimes & 61 & 6.1 \\
\hline & Always & 15 & 1.5 \\
\hline I have tried to commit suicide before & Never & 972 & 96.7 \\
\hline & Sometimes & 26 & 2.6 \\
\hline & Always & 7 & .7 \\
\hline & Never & 956 & 95.1 \\
\hline
\end{tabular}




\begin{tabular}{|c|c|c|c|c|c|c|}
\hline & & & & & & \\
\hline & on between sı & ride and $d$ & pression & & & \\
\hline & & no depre & sion & depressic & & $P$ value \\
\hline & & Number & $\%$ & Number & $\%$ & \\
\hline I think of death and wish to die & Never & 376 & 50.81 & 364 & 49.19 & $<0.001^{*}$ \\
\hline & Sometimes & 29 & 12.89 & 196 & 87.11 & \\
\hline & Always & 2 & 5.00 & 38 & 95.00 & \\
\hline During the past few weeks, I & Never & 400 & 43.06 & 529 & 56.94 & $<0.001^{*}$ \\
\hline & Sometimes & 5 & 8.20 & 56 & 91.80 & \\
\hline & Always & 2 & 13.33 & 13 & 86.67 & \\
\hline I have a clear plan to commit & Never & 403 & 41.46 & 569 & 58.54 & $0.001 *$ \\
\hline & Sometimes & 1 & 3.85 & 25 & 96.15 & \\
\hline & Always & 3 & 42.86 & 4 & 57.14 & \\
\hline I have tried to commit suicide & Never & 397 & 41.53 & 559 & 58.47 & $0.012^{\star}$ \\
\hline & Sometimes & 8 & 19.05 & 34 & 80.95 & \\
\hline & Always & 2 & 28.57 & 5 & 71.43 & \\
\hline * Significant $p$ value & & & & & & \\
\hline
\end{tabular}




\section{Table 6}

Relation between Death wishes and suicidal thinking with depression and anxiety disorders I have thought about death, and I want to die.

\begin{tabular}{|c|c|c|c|c|c|}
\hline & & \multirow[t]{2}{*}{ OR } & \multicolumn{2}{|l|}{$95 \% \mathrm{Cl}$} & \multirow[t]{2}{*}{$P$ value } \\
\hline & & & Lower & Upper & \\
\hline \multirow[t]{2}{*}{ Depression } & no depression** & 1.00 & & & \multirow[t]{2}{*}{$<0.001^{\star}$} \\
\hline & depression & 7.797 & 5.219 & 11.648 & \\
\hline \multirow[t]{2}{*}{ Severe depression } & no depression** & 1 & & & \multirow[t]{2}{*}{$<0.001^{\star}$} \\
\hline & severe depression & 12.123 & 8.055 & 18.247 & \\
\hline \multirow[t]{2}{*}{ anxiety } & no anxiety $\star \star$ & & & & \multirow[t]{2}{*}{$<0.001^{\star}$} \\
\hline & anxiety & 3.767 & 2.734 & 5.190 & \\
\hline \multirow[t]{2}{*}{ Severe anxiety } & No severe anxiety** & & & & \multirow[t]{2}{*}{$<0.001^{\star}$} \\
\hline & Severe anxiety & 3.425 & 2.512 & 4.671 & \\
\hline \multicolumn{6}{|c|}{ During the past few weeks, I thought about suicide } \\
\hline \multirow[t]{2}{*}{ Depression } & no depression** & 1.00 & & & \multirow[t]{2}{*}{$<0.001^{*}$} \\
\hline & depression & 7.453 & 3.389 & 16.394 & \\
\hline \multirow[t]{2}{*}{ Severe depression } & no severe depression $\star \star$ & 1 & & & \multirow[t]{2}{*}{$<0.001^{\star}$} \\
\hline & severe depression & 8.361 & 5.103 & 13.702 & \\
\hline \multirow[t]{2}{*}{ anxiety } & no anxiety** & & & & \multirow[t]{2}{*}{$<0.001^{\star}$} \\
\hline & anxiety & 5.363 & 2.795 & 10.292 & \\
\hline \multirow[t]{2}{*}{ Severe anxiety } & 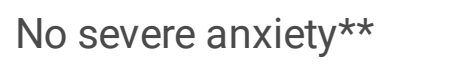 & & & & \multirow[t]{2}{*}{$<0.001^{\star}$} \\
\hline & Severe anxiety & 3.260 & 2.024 & 5.250 & \\
\hline
\end{tabular}

